Check for updates

Cite this: RSC Adv., 2018, 8, 14056

Received 15th March 2018

Accepted 29th March 2018

DOI: $10.1039 / \mathrm{c} 8 \mathrm{ra02268b}$

rsc.li/rsc-advances

\section{Reducing the barrier effect of graphene sheets on a Ag cocatalyst to further improve the photocatalytic performance of $\mathrm{TiO}_{2} \dagger$}

\author{
Juanjuan Ma, Chaocun Zhou, Jinlin Long, (D) Zhengxin Ding, Rusheng Yuan (DD \\ and Chao Xu (DD *
}

Graphene-based cocatalysts can improve the photocatalytic properties of semiconductors, but sometimes, they also function as barrier-like materials, influencing the photoactivity of composites. However, in a multicocatalyst system, less attention is paid to these negative effects of graphene on the performance of other cocatalysts. In this study, by adjusting the loading sequence of graphene and Ag cocatalyst on the surface of $\mathrm{TiO}_{2}$ spheres, the barrier effect of graphene sheets on Ag nanoparticles could be controlled effectively. As a result, these ternary composites with almost no Ag nanoparticles wrapped by graphene possessed improved properties for the photocatalytic reduction of nitro-aromatics as compared to those with some Ag nanoparticles covered by graphene. Furthermore, this phenomenon of barrier effect caused by graphene could be found in the control reaction with metal silver as the main catalyst; this indicated that by avoiding the possible negative influence of graphene on other cocatalysts, the properties of composites with graphene-containing multi cocatalysts could be further improved.

\section{Introduction}

In recent years, graphene-based sheets have been widely used as cocatalysts to improve the photocatalytic properties of semiconductors due to their unique physicochemical properties. ${ }^{\mathbf{1 - 4}}$ To expand their application in photocatalysis areas, graphenecontaining binary cocatalysts, in particular those combined with noble metal nanoparticles (such as $\mathrm{Au}$ and $\mathrm{Ag}$ ), have also been adopted to modify the semiconductor photocatalysts such as $\mathrm{ZnO}, \mathrm{TiO}_{2}, \mathrm{Bi}_{2} \mathrm{WO}_{6}, \mathrm{La}_{2} \mathrm{Ti}_{2} \mathrm{O}_{7}$, etc. ${ }^{5-22}$ Owing to good electron collection/transport abilities and light response properties of both graphene sheets and noble nanoparticles, these multicocatalysts exhibit combined or synergistic effects on improving the performance of these semiconductors in many photocatalytic reactions.

Generally, there are three strategies to obtain graphene and metal-containing composite photocatalysts: (1) using graphene sheets to wrap the metal-loaded semiconductors, ${ }^{5-9}$ (2) using metal nanoparticles to modify graphene-semiconductor composites, ${ }^{10-17,23,24}$ and (3) using a one-step synthesis process, for example, a solvothermal method, to prepare these ternary composites. ${ }^{25-30}$ Although all these methods can produce graphene/metal-containing photocatalysts, the relative

State Key Laboratory of Photocatalysis on Energy and Environment, College of Chemistry, Fuzhou University, Fuzhou 350002, P. R. China. E-mail: cxu@fzu.edu.cn $\dagger$ Electronic supplementary information (ESI) available: AFM images of small GO sheets, XRD, Raman spectra and thermogravimetric analysis of samples, yield of 4-aminophenol of corresponding experiments. See DOI: 10.1039/c8ra02268b positions of these two kinds of cocatalysts on the surface of semiconductors may be slightly different. Since the size of graphene sheets is usually larger than that of metal nanoparticles, there are two typical position states for these two cocatalysts on the surface of the as-modified photocatalysts, in which graphene sheets may or may not wrap the metal nanoparticles, as shown in Fig. 1.

It has been demonstrated that graphene sheets usually function as protecting layers or barriers to hinder the interactions between substances due to their inherent inert characteristics. ${ }^{31-37}$ For example, enwrapping a bacteria in graphenebased sheets could protect the bacteria from outside
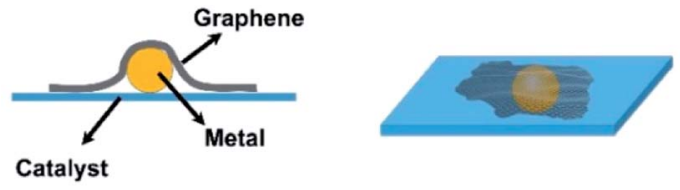

(a) Metal wrapped by graphene
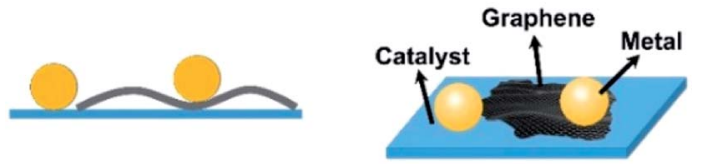

(b) Metal un-wrapped by graphene

Fig. 1 Schematic of the two typical positions of graphene and metal nanoparticles on the surface of photocatalysts: metal nanoparticles (a) wrapped and (b) not wrapped by graphene sheets. 
distractions. Analogously, it could be speculated that in the graphene and metal binary cocatalyst system, when wrapped by graphene sheets (Fig. 1(a)), the noble metal nanoparticles could be protected by these sheets. On the other hand, it is noted that the work functions of graphene and noble metal nanoparticles are different; this can make the electrons to be readily trapped by these noble metal nanoparticles. ${ }^{\mathbf{1 0 , 1 1}}$ Thus, the photogenerated electrons that gathered in noble metal nanoparticles could be restricted by graphene sheets to contact the reactants; this might influence the chemical reactions on the surface of these metals, especially those driven by these energetic electrons. However, to date, less attention has been paid to the potential influence of these structural differences of graphene/metal cocatalysts on property improvement of photocatalysts.

Herein, graphene sheets and Ag nanoparticles were used as cocatalysts to modify $\mathrm{TiO}_{2}$ spheres, and the photocatalytic reduction of nitro-aromatics to amino-aromatics was chosen as the model reaction. Moreover, two typical composite structures were prepared by adjusting the loading sequence of graphene and $\mathrm{Ag}$ nanoparticles on the surface of $\mathrm{TiO}_{2}$. It was found that when $\mathrm{Ag}$ nanoparticles were loaded first, some of these metal nanoparticles were covered by the subsequently loaded graphene sheets. On the other hand, when the loading order was reversed, most of the $\mathrm{Ag}$ nanoparticles were not covered by graphene sheets. Due to wrapping by graphene sheets, the function of $\mathrm{Ag}$ in the reaction system was influenced, and the photocatalytic reduction properties of these composites were inferior to those in the case when graphene sheets were loaded first followed by $\mathrm{Ag}$ nanoparticles, with the same dosage of the two cocatalysts. Moreover, this barrier effect caused by graphene exists in the typical control reaction using Ag as the main catalyst. Thus, elimination of the possible barrier effects of graphene on the other cocatalyst would be a promising way to further improve the photocatalytic properties of the as-obtained composite, which can be extended to other graphene-involved multi-component catalysis systems in the future.

\section{Experimental}

\section{Materials}

Graphite flakes (325 mesh) were purchased from Alfa Aesar Chemical Corporation. Tetrabutyl titanate (98\%), silver nitrate (99.8\%), formic acid (98\%), and sodium borohydride (96\%) were purchased from Shanghai Chemical Corporation. (3Aminopropyl)-trimethoxysilane (97\%) and 4-nitrophenol (99.5\%) were purchased from Aladdin Chemical Corporation. All chemicals were used without further treatment.

\section{Preparation of graphene oxide and $\mathrm{TiO}_{2}$ spheres}

Graphene oxide (GO) sheets were prepared from natural graphite using Hummers method, ${ }^{38}$ and small GO sheets (about 300-400 nm) were obtained through sonication and centrifugation. ${ }^{39,40} \mathrm{TiO}_{2}$ spheres were synthesized using the method reported by Yin and co-authors ${ }^{\mathbf{4 1 , 4 2}}$ and then modified by (3aminopropyl)-trimethoxysilane (APTMS). The details about the preparation of small GO sheets and modification of $\mathrm{TiO}_{2}$ can be found in our previous study. ${ }^{36}$

\section{Preparation of graphene or Ag-containing $\mathrm{TiO}_{2}$ binary composites}

Graphene-wrapped $\mathrm{TiO}_{2}$ samples (labeled as TG) were also prepared according to our previous studies. Typically, a GO dispersion (1.5 mL, $0.33 \mathrm{mg} \mathrm{mL}^{-1}$ ) was added to a $\mathrm{TiO}_{2}$ suspension (50 mg of modified $\mathrm{TiO}_{2}$ was dispersed in $50 \mathrm{~mL}$ of water), which was stirred for $12 \mathrm{~h}$ at room temperature to form GO-wrapped $\mathrm{TiO}_{2}$ composites (labeled as $\mathrm{TGO}_{0.5}$ ). After this, $\mathrm{TGO}_{0.5}$ samples that were dried at $60{ }^{\circ} \mathrm{C}$ were redispersed in ethanol $(50 \mathrm{~mL})$ and then irradiated with ultraviolet light $(16 \mathrm{~W}$, Philips TUV-4W with a wavelength of around $254 \mathrm{~nm}$ ) for $2 \mathrm{~h}$ under a $\mathrm{N}_{2}$ atmosphere to obtain $\mathrm{TG}_{0.5}$ composites.

Ag-modified $\mathrm{TiO}_{2}$ composites were prepared using a modified photo-deposition method. For example, a $\mathrm{AgNO}_{3}$ solution $\left(1.0 \mathrm{~mL}, 0.78 \mathrm{mg} \mathrm{mL}^{-1}\right)$ was added to $\mathrm{a} \mathrm{TiO}_{2}$ suspension $(100 \mathrm{mg}$ of modified $\mathrm{TiO}_{2}$ was dispersed in $100 \mathrm{~mL}$ of ethanol), and the mixed liquid was irradiated with the same ultraviolet light for $2 \mathrm{~h}$ under a $\mathrm{N}_{2}$ atmosphere. The as-formed $\mathrm{Ag}$-decorated $\mathrm{TiO}_{2}$ samples were labeled as $\mathrm{TA}_{0.5}$. The subscript in these abbreviations was the added content of GO or/and $\mathrm{Ag}$, and the other graphene or Ag-containing composites with different contents of graphene or Ag were prepared through the same process.

\section{Preparation of graphene/Ag-containing $\mathrm{TiO}_{2}$ ternary composites}

The as-obtained binary samples were used as starting materials to prepare our ternary composites. The preparation process of graphene-wrapped TA composites was similar to that of TG, but the pure $\mathrm{TiO}_{2}$ spheres were replaced by TA samples, and the final composites were labeled as $\mathrm{TA}_{x} \mathrm{G}_{y}(x$ and $y$ wt $\%$ were the added contents of Ag and GO, respectively). Similarly, when Agmodified TG samples were constructed, TGO composites were used as precursors for loading Ag nanoparticles. The photodeposition process of $\mathrm{Ag}$ was consistent with that of TA samples, and the as-prepared ternary samples were labeled as $\mathrm{TG}_{x} \mathrm{~A}_{y}$.

\section{Photocatalytic reduction of 4-nitrophenol}

In a typical reaction, $\mathrm{TiO}_{2}$-based samples (ca. $40 \mathrm{mg}$ ) and formic acid $(30 \mu \mathrm{L})$ were added to a 4-nitrophenol solution $(80 \mathrm{~mL}, 12$ $\mathrm{ppm}$ ) in a quartz vial. Then, the suspensions were stirred in dark for $0.5 \mathrm{~h}$ under $\mathrm{N}_{2}$ protection. Ultraviolet light (16 W, Philips TL-4W with a wavelength of around $365 \mathrm{~nm}$ ) was used as the irradiation source. At a given time interval of light irradiation, the reaction solution was withdrawn and filtered, and the filtrate with the products was analyzed by high-performance liquid chromatography (Waters-2998).

\section{Reduction of 4-nitrophenol by $\mathrm{NaBH}_{4}$}

Control tests were carried out according to our previous study. ${ }^{43}$ Typically, aqueous solutions of 4-nitrophenol $(0.21 \mathrm{~mL}, 100$ ppm) and $\mathrm{NaBH}_{4}\left(0.2 \mathrm{~mL}, 3.8 \mathrm{mg} \mathrm{mL} \mathrm{mL}^{-1}\right)$ were added to 
deionized water $(2.5 \mathrm{~mL})$ in a quartz cuvette. Then, $\mathrm{TiO}_{2}$ with different contents of graphene and $\mathrm{Ag}$ (0.36 $\mathrm{mg}$ dispersed in $0.18 \mathrm{~mL}$ of water) was added. After proceeding the reaction for a certain time, the solution was filtered, and the filtrate was analyzed by UV-vis spectroscopy (Thermo Fisher scientific, Genesys 10S).

\section{Characterization}

X-ray diffraction (XRD) measurements were performed using a diffractometer (Bruker D8 Advance) with $\mathrm{Cu} \mathrm{K} \alpha$ radiation. Thermogravimetric tests were performed using a thermogravimetric analyzer (Mettler Toledo) from 25 to $800{ }^{\circ} \mathrm{C}$ at the heating rate of $5{ }^{\circ} \mathrm{C} \mathrm{min}^{-1}$ in an air flow. Inductively coupled plasma spectroscopy (ICP, Thermo Fisher Scientific Xseries 2) was used to investigate the content of the metal component. The zetapotentials of samples were tested by the Malvern Zetasizer Nano-ZS90 particle analyzer. Atomic force microscopy (AFM, Dimension Icon Bruker) in tapping mode was used to measure the size of the GO flakes. X-ray photoelectron spectroscopy (XPS) studies were carried out via a Thermo Scientific Escalab $250 \mathrm{X}$ ray photoelectron spectrometer using $\mathrm{Mg} \mathrm{K} \alpha(h \nu=1253.6 \mathrm{eV}) \mathrm{X}$ ray as the excitation source. Raman spectra were obtained from 200 to $2000 \mathrm{~cm}^{-1}$ via a Raman microprobe (Renishaw Invia) using a $514.5 \mathrm{~nm}$ argon ion laser. The morphology of composites was analyzed by a transmission electron microscope (TEM, Tecnai G2 F20 S-TWIN) and a field emission scanning electron microscope (FESEM, Hitachi S8010). Photo-electrochemical measurements were carried out using the Autolab electrochemical workstation in a three-electrode cell with $0.2 \mathrm{M}$ $\mathrm{Na}_{2} \mathrm{SO}_{4}$ as the electrolyte. $\mathrm{Ag} / \mathrm{AgCl}$ in saturated $\mathrm{KCl}$ and $\mathrm{Pt}$ wire were used as the reference and counter electrodes, respectively. Indium-tin oxide glasses coated with samples were used as the working electrodes. UV light was generated by a $500 \mathrm{~W}$ xenon lamp (Beijin Perfectlight, CHF-XM500), and a $0.5 \mathrm{M} \mathrm{KCl} \mathrm{solu-}$ tion containing $0.01 \mathrm{M} \mathrm{K}_{3}\left[\mathrm{Fe}(\mathrm{CN})_{6}\right] / \mathrm{K}_{4}\left[\mathrm{Fe}(\mathrm{CN})_{6}\right]$ was utilized to investigate the Nyquist impedance.

\section{Results and discussion}

As is known, there are many methods to prepare graphene and metal-containing ternary composite photocatalysts. However, less attention is paid to the potential structural difference (derived from the loading strategy) of these two kinds of cocatalysts in composites. In this study, we loaded graphene and metal nanoparticles on semiconductors by a stepwise method. The process for loading each cocatalyst was almost the same, but the loading sequence was reversed. Moreover, to enable graphene sheets to better wrap the metal nanoparticles on the surface of semiconductors, small GO sheets (less than $400 \mathrm{~nm}$, as shown in the AFM images in Fig. S1, ESI $\dagger$ ) and $\mathrm{TiO}_{2}$ spheres $(400 \mathrm{~nm})$ were chosen as the starting materials to construct ternary composites based on our previous research. ${ }^{36}$ In our composite systems, $\mathrm{Ag}$ nanoparticles were decorated on the surface of $\mathrm{TiO}_{2}$ spheres (or GO-wrapped $\mathrm{TiO}_{2}$ ) by traditional photo-deposition methods in an ethanol solution. On the other hand, these GO sheets (zeta-potential was about $-17 \mathrm{mV}$ ) that were enwrapping $\mathrm{TiO}_{2}(+22 \mathrm{mV})$ or $\mathrm{Ag}$-modified $\mathrm{TiO}_{2}$ spheres $(+21 \mathrm{mV})$ through electrostatic adsorption were reduced by a photo-reduction strategy according to previous studies. ${ }^{44-47}$

Fig. 2 displays the TEM images of two typical ternary composites obtained by different loading sequences of GO and $\mathrm{Ag}$ nanoparticles on $\mathrm{TiO}_{2}$ spheres (the added dosages of both GO and $\mathrm{Ag}$ are $0.5 \mathrm{wt} \%$, and XRD patterns of the samples are shown in Fig. S2 $\dagger$ ). From these images, it was found that both graphene and $\mathrm{Ag}$ particles existed on the surface of $\mathrm{TiO}_{2}$ spheres (which could also be supported by the wide-survey XPS spectra, Fig. 3A), but with tiny structural differences. In particular, when ternary composites were obtained by pasting graphene sheets on $\mathrm{Ag}-\mathrm{TiO}_{2}$ composites $\left(\mathrm{TA}_{0.5} \mathrm{G}_{0.5}\right)$, some $\mathrm{Ag}$ nanoparticles on the surface of $\mathrm{TiO}_{2}$ were covered by these subsequently loaded graphene sheets, as shown with arrows in Fig. 2(a) and (b). Certainly, this enwrapping process of graphene on the surface of Ag-modified $\mathrm{TiO}_{2}$ was random; thus, not every $\mathrm{Ag}$ nanoparticle was covered by these carbon sheets. By contrast, since the graphene sheets were already attached on the surface of the $\mathrm{TiO}_{2}$ spheres, these subsequently loaded Ag nanoparticles were inclined to load on the surface of the composite spheres. As shown in Fig. 2(c) and (d), almost all the Ag nanoparticles were exposed in $\mathrm{TG}_{0.5} \mathrm{~A}_{0.5}$ composites, which were not covered by the already loaded graphene sheets. In theory, it is possible that $\mathrm{Ag}$ nanoparticles can decorate the surface of pasted graphene due to its electron collection ability. However, these subsequently loaded Ag nanoparticles could still be considered as unwrapped (Fig. 1(b)).

Although the loading order of graphene and Ag was reversed, their characteristics in the final composites were almost the same (Fig. 2, 3, S2 and S3†). For example, from TEM images, we can find that the sizes of the photo-deposited $\mathrm{Ag}$ nanoparticles in both $\mathrm{TG}_{0.5} \mathrm{~A}_{0.5}$ and $\mathrm{TA}_{0.5} \mathrm{G}_{0.5}$ samples are similar to each
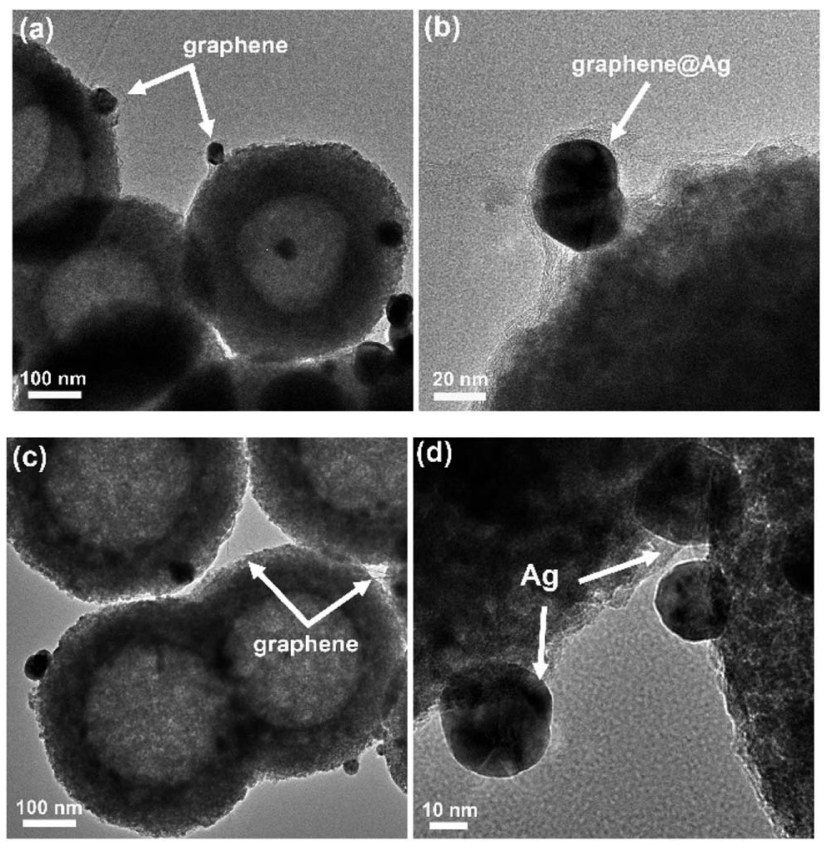

Fig. 2 TEM images of the samples. (a) and (b) $\mathrm{TA}_{0.5} \mathrm{G}_{0.5}$, (c) and (d) $\mathrm{TG}_{0.5} \mathrm{~A}_{0.5}$ 
other, which are about $30 \mathrm{~nm}$. Moreover, the inductively coupled plasma analysis suggested a similar content of $\mathrm{Ag}$ in these two composites. To investigate the changes in GO sheets during the preparation process, we also carried out XPS and Raman analyses. Fig. 3B shows the C1s XPS spectra of the typical $\mathrm{TG}_{0.5} \mathrm{~A}_{0.5}$ and $\mathrm{TA}_{0.5} \mathrm{G}_{0.5}$ samples, and $\mathrm{TA}_{0.5} \mathrm{GO}_{0.5}$ is used as the control sample. As is known, after a certain degree of reduction, the areas of oxygen-containing functional groups decrease in the C1s spectra. ${ }^{48,49}$ By comparing the changes in these groups $(\mathrm{C}-\mathrm{O} / \mathrm{C}=\mathrm{O})$ in the $\mathrm{TA}_{0.5} \mathrm{GO}_{0.5}$ and $\mathrm{TA}_{0.5} \mathrm{G}_{0.5}$ samples, it was found that these added GO sheets could be reduced through photocatalytic reduction (Fig. 3B(a) and (b)), which was consistent with previous studies. ${ }^{\mathbf{4 4 5}}$ Moreover, similar C1s spectra in both $\mathrm{TA}_{0.5} \mathrm{G}_{0.5}$ and $\mathrm{TG}_{0.5} \mathrm{~A}_{0.5}$ indicated that GO sheets in these two kinds of ternary composites possessed approximately the same reduction degree, which could be further supported by Raman results (Fig. S3†) ${ }^{50,51}$ In addition, the contents of graphene sheets in $\mathrm{TA}_{0.5} \mathrm{G}_{0.5}$ and $\mathrm{TG}_{0.5} \mathrm{~A}_{0.5}$ composites were similar to each other, which were confirmed by thermogravimetric analysis (Fig. S4 $\dagger$ ).

It was shown that the characteristics of each kind of cocatalyst were similar; however, the structures, especially the relative positions, of graphene and $\mathrm{Ag}$ were indeed different in
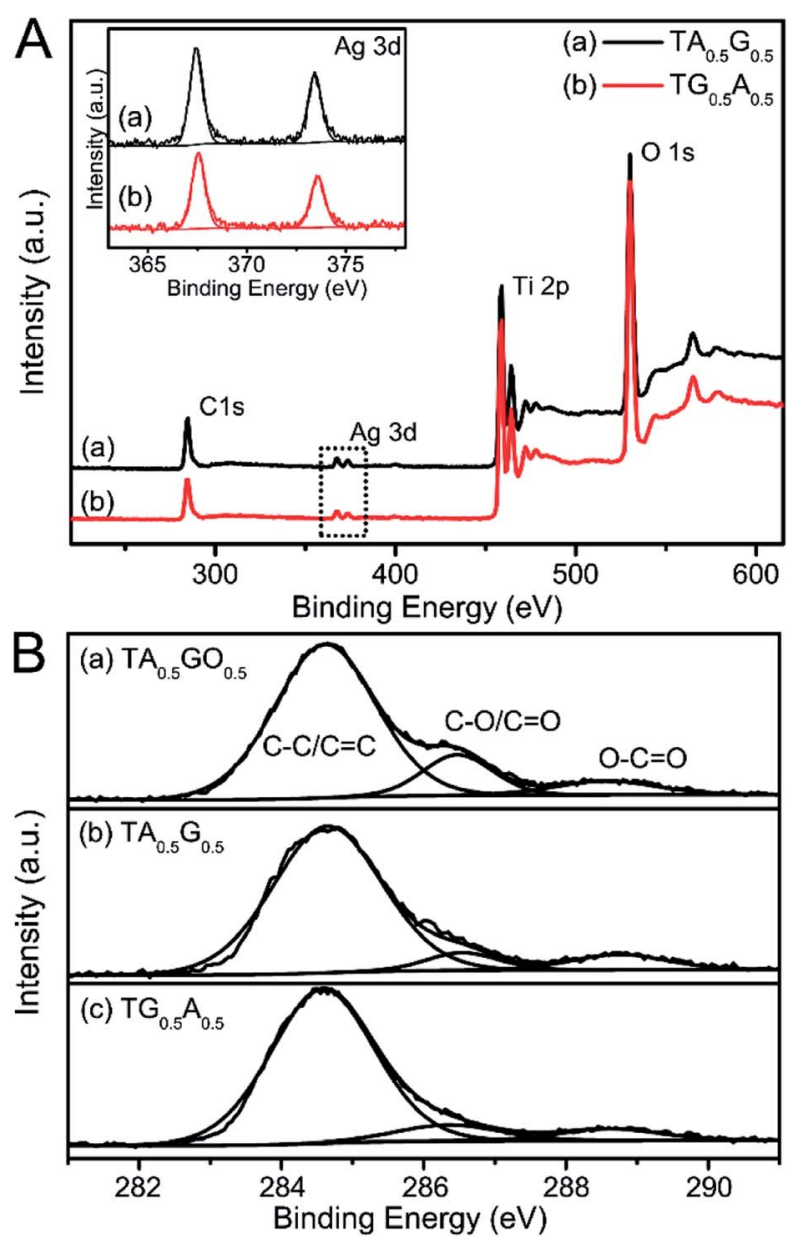

Fig. 3 (A) The wide-survey XPS spectra of (a) $\mathrm{TA}_{0.5} \mathrm{G}_{0.5}$ and (b) $\mathrm{TG}_{0.5}$ $A_{0.5}$. Inset shows the Ag $3 d$ XPS spectra of samples. (B) C1 XPS spectra of (a) $\mathrm{TA}_{0.5} \mathrm{GO}_{0.5}$, (b) $\mathrm{TA}_{0.5} \mathrm{G}_{0.5}$, and (c) $\mathrm{TG}_{0.5} \mathrm{~A}_{0.5}$. these two kinds of ternary composites (as suggested by TEM images in Fig. 2). Unfortunately, in most composites, these subtle differences in structures have not attracted enough attention, and their influence on the photocatalysis performance has not been considered.

As demonstrated in many studies, either graphene sheets or noble metals can improve the photocatalytic reduction performance of semiconductors for reducing nitro-aromatics to corresponding amino-aromatics with the assistance of a hole scavenger; this is mainly due to their excellent photo-generated charge separation/transport abilities..$^{36,52,53} \mathrm{We}$ also carried out similar tests using graphene or Ag-modified $\mathrm{TiO}_{2}$ samples as control photocatalysts. It was found that when the content of GO or $\mathrm{Ag}$ was about $0.5 \mathrm{wt} \%$ in our system, $\mathrm{TG}_{0.5}$ or $\mathrm{TA}_{0.5}$ composites possessed optimal photocatalytic reduction properties as compared to pure $\mathrm{TiO}_{2}$ (Fig. 5A). Certainly, when graphene and $\mathrm{Ag}$ were utilized together to modify $\mathrm{TiO}_{2}$, the asobtained ternary composites possessed higher photocatalytic reduction abilities as compared to $\mathrm{TiO}_{2}$ with a single cocatalyst; this was probably due to the combined effects of these two cocatalysts. Fig. 4A summarizes the photocatalytic performances of some typical composites towards the reduction of 4-
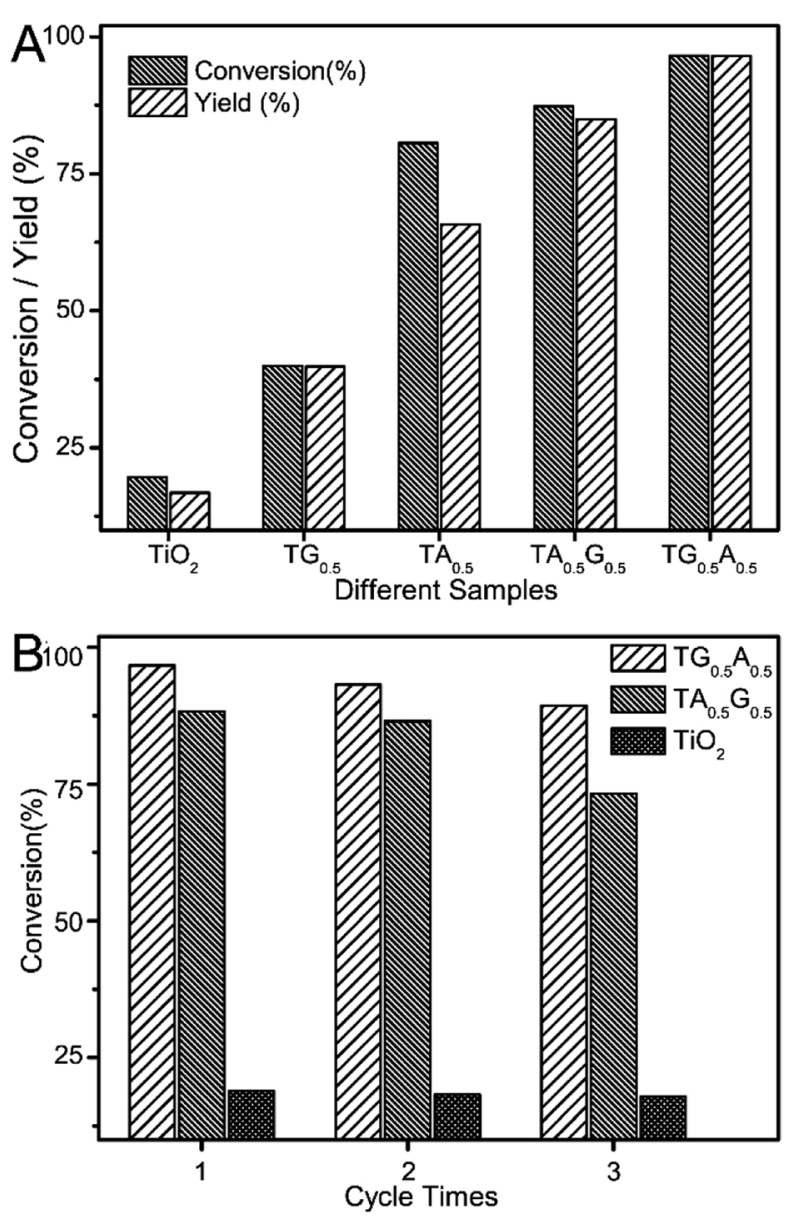

Fig. 4 (A) Photocatalytic conversion of 4-nitrophenol to 4-aminophenol using some typical composites. The content of GO and/or Ag was about $0.5 \mathrm{wt} \%$ in all the composite photocatalysts. (B) Conversion rate of recycle experiments using $\mathrm{TG}_{0.5} \mathrm{~A}_{0.5}, \mathrm{TA}_{0.5} \mathrm{G}_{0.5}$ and $\mathrm{TiO}_{2}$ as photocatalysts. 

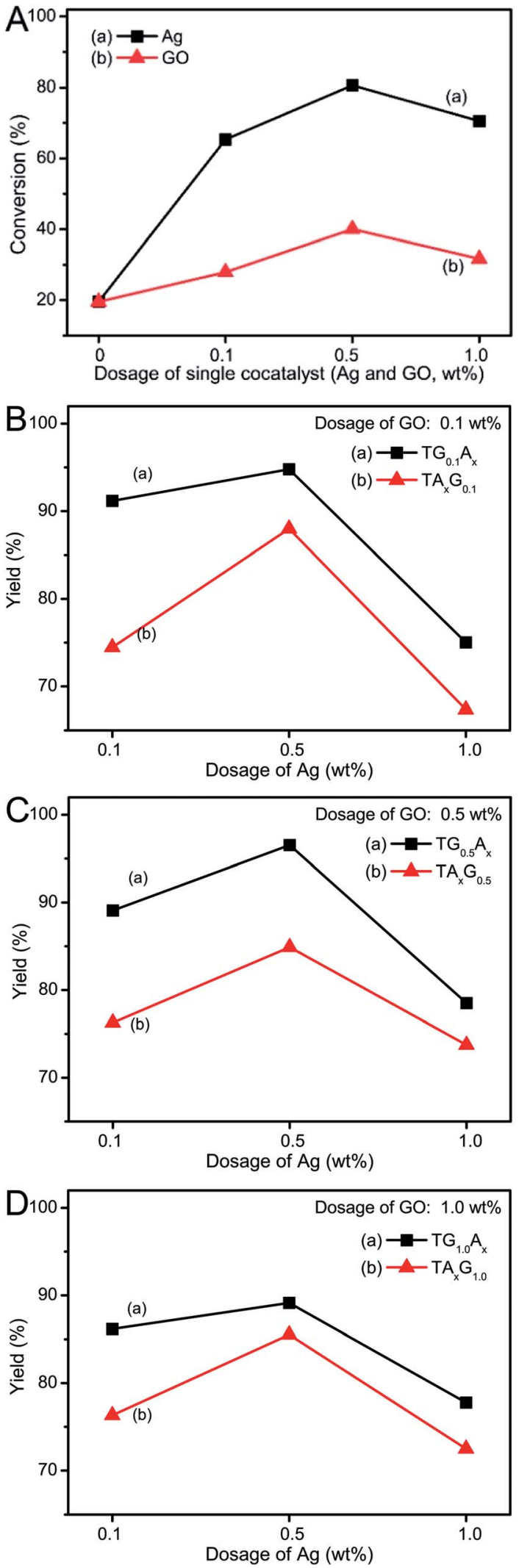

Fig. 5 Photocatalytic conversion of 4-nitrophenol using different composites. (A) $\mathrm{TiO}_{2}$ with a single cocatalyst (a) $\mathrm{Ag}$ and (b) graphene; $(B-D)$ the dosage of GO sheets in each figure was fixed, which was 0.1, 0.5 and 1.0 wt\% in (B), (C), and (D) respectively. However, the dosage of $\mathrm{Ag}$ was adjusted from 0.1 to $1.0 \mathrm{wt} \%$ in the two kinds of ternary composites: (a) TGA and (b) TAG samples.
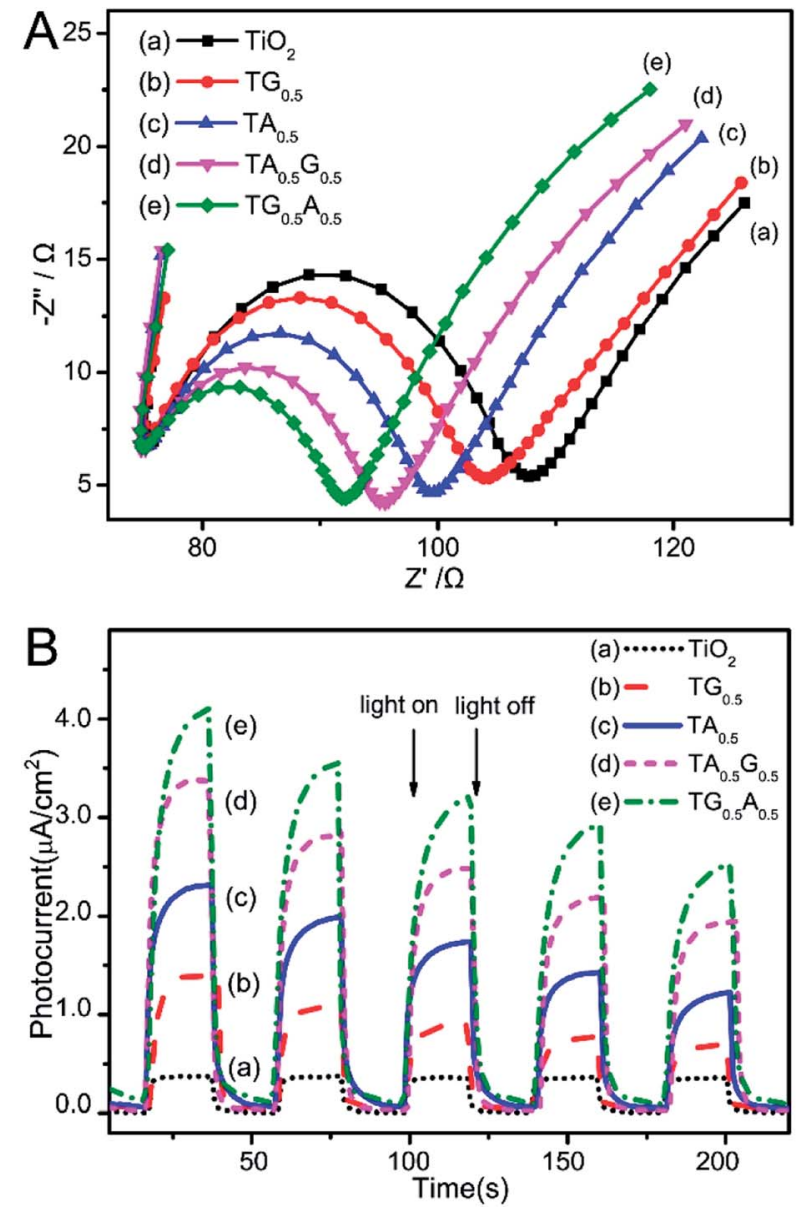

Fig. 6 (A) Nyquist impedance plots and (B) photocurrent signals of the samples. (a) $\mathrm{TiO}_{2}$, (b) $\mathrm{TG}_{0.5}$, (c) $\mathrm{TA}_{0.5}$, (d) $\mathrm{TA}_{0.5} \mathrm{G}_{0.5}$, and (e) $\mathrm{TG}_{0.5} \mathrm{~A}_{0.5}$.

nitrophenol to 4 -aminophenol. It could be clearly seen that the photocatalytic performance of $\mathrm{TA}_{0.5} \mathrm{G}_{0.5}$ or $\mathrm{TG}_{0.5} \mathrm{~A}_{0.5}$ samples with two cocatalysts was higher than that with a single cocatalyst $\left(\mathrm{TA}_{0.5}\right.$ and $\left.\mathrm{TG}_{0.5}\right)$.

It is worth noting that there are some differences between the catalytic activities of $\mathrm{TA}_{0.5} \mathrm{G}_{0.5}$ and $\mathrm{TG}_{0.5} \mathrm{~A}_{0.5}$ composites. By comparison, the conversion of 4-nitrophenol using $\mathrm{TG}_{0.5} \mathrm{~A}_{0.5}$ composite was $c a .97 \%$ after irradiation for $9 \mathrm{~min}$, which was about 10 points higher than that of $\mathrm{TA}_{0.5} \mathrm{G}_{0.5}$. Fig. $4 \mathrm{~B}$ shows the recycle experiment results of the two typical ternary composites. The photocatalytic activities of each composite decreased slightly after every recycle experiment; this was probably due to mass loss of the catalysts. However, the photocatalytic performance of $\mathrm{TG}_{0.5} \mathrm{~A}_{0.5}$ was always higher than that of the $\mathrm{TA}_{0.5} \mathrm{G}_{0.5}$ samples after each cycle (the corresponding yield of 4-aminophenol is listed in Fig. S5 $\dagger$ ).

Furthermore, we investigated the photocatalytic reduction properties of other ternary composites with different contents of graphene and $\mathrm{Ag}$ nanoparticles, and the corresponding results are summarized in Fig. 5 (B-D). As expected, these results still supported the fact that when the dosages of each cocatalysts were the same, the photoactivity of Ag-modified graphene-wrapped $\mathrm{TiO}_{2}$ spheres $\left(\mathrm{TG}_{y} \mathrm{~A}_{x}\right)$ was always higher than that of the graphene-wrapped $\mathrm{Ag}-\mathrm{TiO}_{2}$ composites $\left(\mathrm{TA}_{x} \mathrm{G}_{y}\right)$. 
(a)

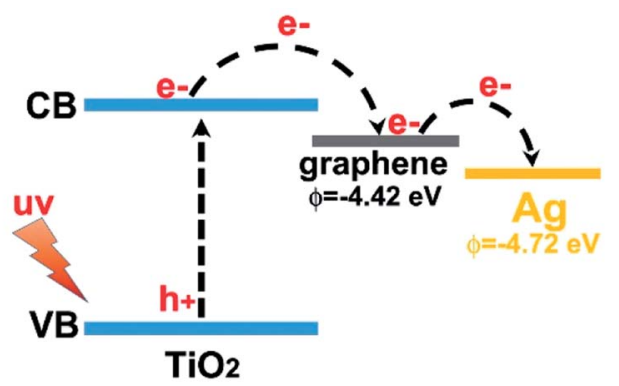

(b)

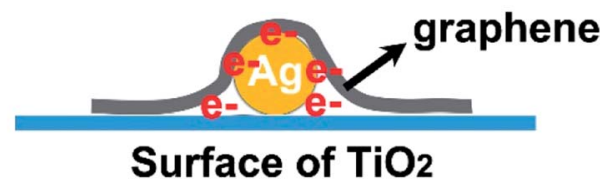

(c)

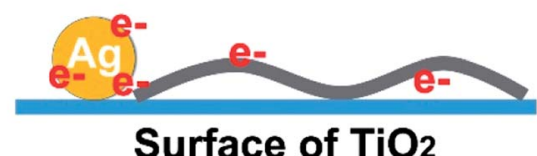

Fig. 7 Schematic showing the proposed mechanisms for (a) the transfer of electrons from different energy levels of the ternary heterostructure, and the proposed states of electrons in the two cocatalysts in (b) TAG and (c) TGA samples.

Taking the dosage of GO precursor as about $0.5 \mathrm{wt} \%$ for example, when the dosage of $\mathrm{Ag}$ was changed from 0.1 to $1.0 \mathrm{wt} \%$, the photocatalytic performance of $\mathrm{TG}_{0.5} \mathrm{~A}_{x}$ was higher than that of $\mathrm{TA}_{x} \mathrm{G}_{0.5}$ (Fig. 5C). Certainly, an analogous tendency was found in other composites when the dosage of GO was adjusted to 0.1 or $1.0 \mathrm{wt} \%$ (Fig. 5B, D and S6†े).

We attribute these differences to the possible barrier effect of graphene sheets on these $\mathrm{Ag}$ nanoparticles that might hinder the effective contact of $\mathrm{Ag}$ with external environment. As demonstrated recently, graphene-based sheets can function as barrier materials owing to their inherent structure and properties. $^{31-37,54}$ Thus, it can be speculated that when graphene sheets encapsulate $\mathrm{Ag}$ nanoparticles on the surface of $\mathrm{TiO}_{2}$, certain surface performances of these $\mathrm{Ag}$ particles can be disturbed by these barrier-like carbon sheets. Fig. 6A shows the results of electrochemical impedance spectroscopy (EIS) experiments of our samples, which demonstrates the chargecarrier migration process at the contact interface between the electrode and electrolyte solution. By comparing the Nyquist plots, especially the signals of the two ternary composites, it was found that the $\mathrm{TG}_{0.5} \mathrm{~A}_{0.5}$ composite possessed more depressed semicircles than $\mathrm{TA}_{0.5} \mathrm{G}_{0.5}$; this indicated that faster interfacial electron transfer was obtained over $\mathrm{TG}_{0.5} \mathrm{~A}_{0.5}$ than that over $\mathrm{TA}_{0.5} \mathrm{G}_{0.5}$; this was probably due to the undisturbed charge transport between the uncovered $\mathrm{Ag}$ nanoparticles and electrolyte in the $\mathrm{TG}_{0.5} \mathrm{~A}_{0.5}$ samples. On the other hand, as is known, both graphene and $\mathrm{Ag}$ can collect photo-generated electrons and promote reactions on their surfaces in photocatalysis systems. However, when graphene sheets are in contact with Ag nanoparticles, photo-electrons are inclined to be trapped by $\mathrm{Ag}$ due to the work function difference between graphene
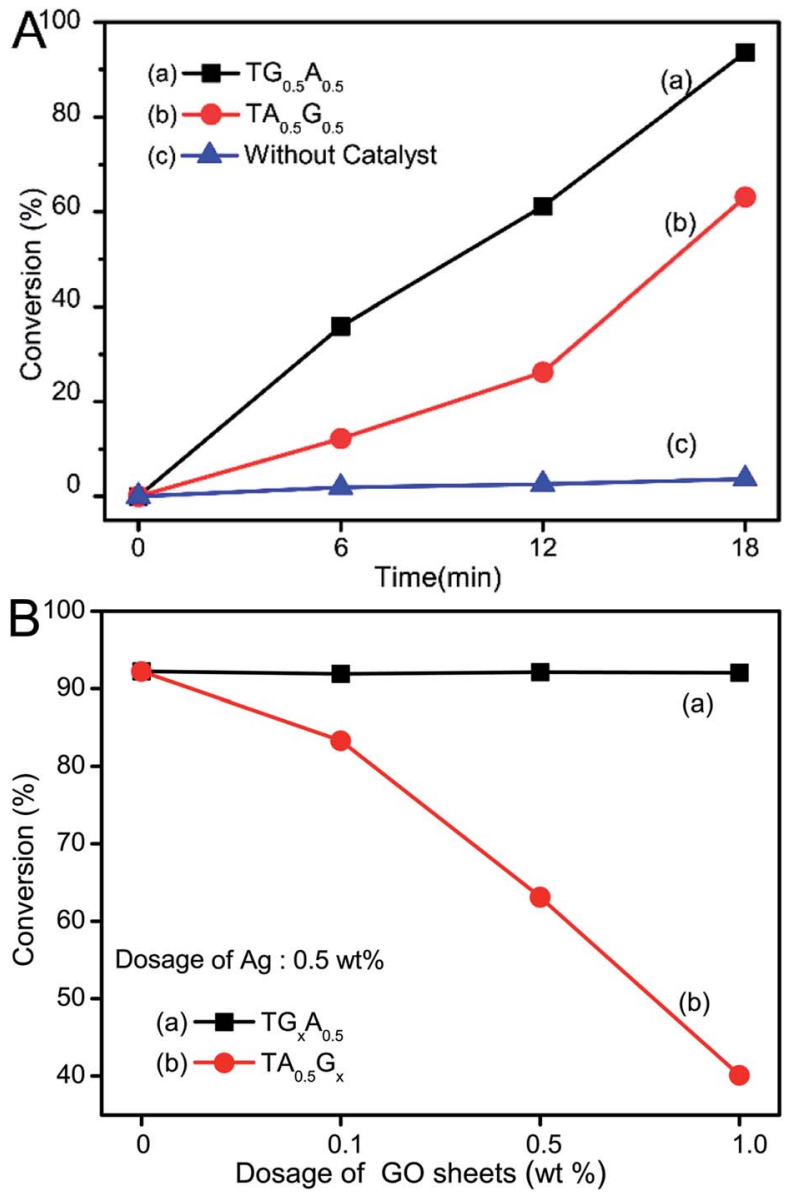

Fig. 8 (A) Conversion rate of 4-nitrophenol as a function of time after the addition of $\mathrm{NaBH}_{4}$ : (a) $\mathrm{TG}_{0.5} \mathrm{~A}_{0.5}$, (b) $\mathrm{TA}_{0.5} \mathrm{G}_{0.5}$, and (c) control test without a catalyst. (B) Conversion rate of 4 -nitrophenol after reaction for 18 min using our samples with different dosages of GO sheets: (a) $\mathrm{TG}_{x} \mathrm{~A}_{0.5}$ and (b) $\mathrm{TA}_{0.5} \mathrm{G}_{x}(x=0,0.1,0.5$, and $1.0 \mathrm{wt} \%)$.

$\left(-4.42 \mathrm{eV}\right.$, vs. vacuum) and $\mathrm{Ag}(-4.72 \mathrm{eV}),{ }^{10,11}$ as shown in the scheme in Fig. 7(a). Thus, the transport and utilization of photogenerated electrons that gather in these Ag nanoparticles could be restrained in these TAG composites. ${ }^{55}$ From the photocurrent results shown in Fig. 6B, it was found that the photocurrent intensity of $\mathrm{TA}_{0.5} \mathrm{G}_{0.5}$ was indeed lower than that of $\mathrm{TG}_{0.5} \mathrm{~A}_{0.5}$ samples in our system. Accordingly, the photocatalytic reactions driven by these photo-generated electrons were also disturbed in the TAG samples; this resulted in a decrease in the catalytic performance as compared to that of the TGA samples.

Furthermore, the barrier effect of graphene sheets on these Ag nanoparticles could be further confirmed by a benchmark reduction of 4-nitrophenol to 4-aminophenol using sodium borohydride as the reductant. ${ }^{43,56-58}$ As is well-known, this reaction is rapid in the presence of metallic surfaces. Thus, it can be speculated that when their surfaces are enwrapped (Fig. 1), the performance of $\mathrm{Ag}$ can be restrained. Taking the $0.5 \mathrm{wt} \%$ dosage of both graphene and $\mathrm{Ag}$ for example, $\mathrm{TG}_{0.5} \mathrm{~A}_{0.5}$ samples could convert $92 \%$ of 4 -nitrophenol after reacting for 18 min (Fig. 8A(a)), whereas only about $60 \%$ of 4 -nitrophenol was converted when $\mathrm{TA}_{0.5} \mathrm{G}_{0.5}$ was used as a catalyst (Fig. $8 \mathrm{~A}(\mathrm{~b})$ ). Moreover, since the $\mathrm{Ag}$ nanoparticles are not wrapped by 
graphene sheets, the catalytic activity of $\mathrm{Ag}$ nanoparticles in $\mathrm{TG}_{x} \mathrm{~A}_{0.5}$ was hardly disturbed by the dosage change of GO sheets (Fig. 8B(a)). However, the catalytic properties of $\mathrm{TA}_{0.5} \mathrm{G}_{x}$ composites decreased obviously with an increase in the dosage of GO sheets (Fig. 8B(b)); this was because more Ag particles on the surface of $\mathrm{TiO}_{2}$ were wrapped by these graphene sheets.

Accordingly, our study has shown that in a graphene/Agcontaining photocatalysis system, the enwrapping of graphene sheets on Ag nanoparticles could be controlled by simply adjusting the loading order of these two kinds of cocatalysts on the surface of $\mathrm{TiO}_{2}$ semiconductors (Fig. 7(b) and (c)). Since Ag nanoparticles are not wrapped by graphene sheets, the features of $\mathrm{Ag}$ as cocatalysts could be developed efficiently; this further improved the photocatalytic performance of these as-obtained ternary composites. While constructing composites containing multi-cocatalysts in the future, the possible negative effects of graphene sheets on other cocatalysts are worth taking into account; this would be helpful to better utilize the functions of the added cocatalysts and improve the properties of composites.

\section{Conclusion}

In this study, we have prepared graphene and Ag-containing $\mathrm{TiO}_{2}$ composite photocatalysts with tiny structural differences by stepwise photoinduced loading methods. When $\mathrm{Ag}$ was loaded on $\mathrm{TiO}_{2}$ first, the subsequently added graphene-based sheets could wrap some Ag nanoparticles. However, when the loading order was reversed, the $\mathrm{Ag}$ nanoparticles were not covered by these pre-coated carbon sheets. Since graphene sheets usually function as barrier-like layers, when they wrap some Ag nanoparticles in TAG samples, the performance of these $\mathrm{Ag}$ particles as cocatalysts is affected, especially the reactions occurring on their surfaces. Based on the results of photocatalytic reduction of 4-nitrophenol, it was shown that these TGA samples with uncovered Ag nanoparticles possessed better photocatalytic properties than the graphene-wrapped TAG composites in the case of the same dosage of these two cocatalysts. Moreover, the barrier effect of graphene in our samples could be found in the typical chemical reduction of 4-nitrophenol using Ag as the catalyst.

Our study demonstrated that in a composite system with graphene-containing multi cocatalysts, by avoiding the potential influence of graphene on other cocatalysts, the properties of composites could be further improved, which provided us a new strategy to construct efficient composite materials in the future.

\section{Conflicts of interest}

There is no conflict of interest.

\section{Acknowledgements}

This work was financially supported by the National Nature Science Foundation of China (21643009) and the Independent Research Project of State Key Laboratory of Photocatalysis on
Energy and Environment (2014B04 and 2017B02), and the program for Qishan Scholar in Fuzhou University (XQS-1505).

\section{Notes and references}

1 Q. J. Xiang, J. G. Yu and M. Jaroniec, Chem. Soc. Rev., 2012, 41, 782-796.

2 M. Zhu, P. Chen and M. Liu, ACS Nano, 2011, 5, 4529-4536.

3 X. Huang, Z. Y. Yin, S. X. Wu, X. Y. Qi, Q. Y. He, Q. C. Zhang, Q. Y. Yan, F. Boey and H. Zhang, Small, 2011, 7, 1876-1902.

4 X. Li, J. G. Yu, S. Wageh, A. A. Al-Ghamdi and J. Xie, Small, 2016, 12, 6640-6696.

5 L. C. Sim, K. H. Leong, S. Ibrahim and P. Saravanan, J. Mater. Chem. A, 2014, 2, 5315-5322.

6 F. Meng, S. K. Cushing, J. Li, S. Hao and N. Wu, ACS Catal., 2015, 5, 1949-1955.

7 N. T. Khoa, S. W. Kim, D.-H. Yoo, S. Cho, E. J. Kim and S. H. Hahn, ACS Appl. Mater. Interfaces, 2015, 7, 3524-3531.

8 F. J. Sheu and C. P. Cho, Int. J. Hydrogen Energy, 2017, 42, 17020-17029.

9 E. Vasilaki, I. Georgaki, D. Vernardou, M. Vamvakaki and N. Katsarakis, Appl. Surf. Sci., 2015, 353, 865-872.

10 P. Roy, A. P. Periasamy, C.-T. Liang and H.-T. Chang, Environ. Sci. Technol., 2013, 47, 6688-6695.

11 J. Low, J. Yu, Q. Li and B. Cheng, Phys. Chem. Chem. Phys., 2014, 16, 1111-1120.

12 Y. Yang, E. Liu, H. Dai, L. Kang, H. Wu, J. Fan, X. Hu and H. Liu, Int. J. Hydrogen Energy, 2014, 39, 7664-7671.

13 P. Gao, K. Ng and D. D. Sun, J. Hazard. Mater., 2013, 262, 826-835.

14 J. Zhang, F.-X. Xiao, G. Xiao and B. Liu, Nanoscale, 2014, 6, 11293-11302.

15 P. Gao, Z. Liu and D. D. Sun, J. Mater. Chem. A, 2013, 1, 14262-14269.

16 X. Lu, J. Shen, J. Wang, Z. Cui and J. Xie, RSC Adv., 2015, 5, 15993-15999.

17 Y. Wen, H. Ding and Y. Shan, Nanoscale, 2011, 3, 4411-4417. 18 P. Borthakur, P. K. Boruah, N. Hussain, Y. Silla and M. R. Das, Appl. Surf. Sci., 2017, 423, 752-761.

19 T.-L. Guo, J.-G. Li, X. Sun and Y. Sakka, Appl. Surf. Sci., 2017, 423, 1-12.

20 A. H. Keihan, R. Hosseinzadeh, M. Farhadian, H. Kooshki and G. Hosseinzadeh, RSC Adv., 2016, 6, 83673-83687.

21 S. Song, B. Cheng, N. Wu, A. Meng, S. Cao and J. Yu, Appl. Catal., B, 2016, 181, 71-78.

22 L. Xiao, L. Youji, C. Feitai, X. Peng and L. Ming, RSC Adv., 2017, 7, 25314-25324.

23 L. Xu, F. Zhang, X. Song, Z. Yin and Y. Bu, J. Mater. Chem. A, 2015, 3, 5923-5933.

24 T. L. Guo, J. G. Li, X. D. Sun and Y. Sakka, Appl. Surf. Sci., 2017, 423, 1-12.

25 L. Xu, Y. Wei, W. Guo, Y. Guo and Y. Guo, Appl. Surf. Sci., 2015, 332, 682-693.

26 M. S. A. S. Shah, K. Zhang, A. R. Park, K. S. Kim, N.-G. Park, J. H. Park and P. J. Yoo, Nanoscale, 2013, 5, 5093-5101.

27 M. Ahmad, E. Ahmed, Z. L. Hong, N. R. Khalid, W. Ahmed and A. Elhissi, J. Alloys Compd., 2013, 577, 717-727. 
28 Y. Wang, J. Yu, W. Xiao and Q. Li, J. Mater. Chem. A, 2014, 2, 3847-3855.

29 A. Datcu, L. Duta, A. Perez del Pino, C. Logofatu, C. Luculescu, A. Duta, D. Perniu and E. Gyoergy, RSC Adv., 2015, 5, 49771-49779.

30 J. Hu, J. Men, Y. Liu, H. Huang and T. Jiao, RSC Adv., 2015, 5, 54028-54036.

31 F. Banhart, ChemPhysChem, 2011, 12, 1637-1639.

32 O. Akhavan, E. Ghaderi and A. Esfandiar, J. Phys. Chem. B, 2011, 115, 6279-6288.

33 R. Kempaiah, S. Salgado, W. L. Chung and V. Maheshwari, Chem. Commun., 2011, 47, 11480-11482.

34 J. Shin, K. Park, W.-H. Ryu, J.-W. Jung and I.-D. Kim, Nanoscale, 2014, 6, 12718-12726.

35 J. S. Lee, K. H. You and C. B. Park, Adv. Mater., 2012, 24, 1084-1088.

36 C. Xu, J. L. Zhu, R. S. Yuan and X. Z. Fu, Carbon, 2016, 96, 394-402.

37 G. Lui, J. Y. Liao, A. S. Duan, Z. S. Zhang, M. Fowler and A. P. Yu, J. Mater. Chem. A, 2013, 1, 12255-12262.

38 W. S. Hummers and R. E. Offeman, J. Am. Chem. Soc., 1958, 80, 1339.

39 U. Khan, A. O'Neill, H. Porwal, P. May, K. Nawaz and J. N. Coleman, Carbon, 2012, 50, 470-475.

40 X. M. Sun, D. C. Luo, J. F. Liu and D. G. Evans, ACS Nano, 2010, 4, 3381-3389.

41 J. B. Joo, I. Lee, M. Dahl, G. D. Moon, F. Zaera and Y. Yin, Adv. Funct. Mater., 2013, 23, 4246-4254.

42 J. B. Joo, M. Dahl, N. Li, F. Zaera and Y. D. Yin, Energy Environ. Sci., 2013, 6, 2082-2092.

43 C. Xu and X. Wang, Colloids Surf., A, 2012, 404, 78-82.

44 O. Akhavan, Carbon, 2011, 49, 11-18.
45 G. Williams, B. Seger and P. V. Kamat, ACS Nano, 2008, 2, 1487-1491.

46 T. S. Wu, S. Liu, Y. L. Luo, W. B. Lu, L. Wang and X. P. Sun, Nanoscale, 2011, 3, 2142-2144.

47 J. W. Jang, S. Cho, G. H. Moon, K. Ihm, J. Y. Kim, D. H. Youn, S. Lee, Y. H. Lee, W. Choi, K. H. Lee and J. S. Lee, Chem.-Eur. J., 2012, 18, 2762-2767.

48 C. Xu, X. Wang and J. W. Zhu, J. Phys. Chem. C, 2008, 112, 19841-19845.

49 H. K. Jeong, Y. P. Lee, R. J. W. E. Lahaye, M. H. Park, K. H. An, I. J. Kim, C. W. Yang, C. Y. Park, R. S. Ruoff and Y. H. Lee, J. Am. Chem. Soc., 2008, 130, 1362-1366.

50 S. Stankovich, D. A. Dikin, R. D. Piner, K. A. Kohlhaas, A. Kleinhammes, Y. Jia, Y. Wu, S. T. Nguyen and R. S. Ruoff, Carbon, 2007, 45, 1558-1565.

51 J. F. Shen, Y. Z. Hu, M. Shi, X. Lu, C. Qin, C. Li and M. X. Ye, Chem. Mater., 2009, 21, 3514-3520.

52 H. Tada, T. Ishida, A. Takao and S. Ito, Langmuir, 2004, 20, 7898-7900.

53 Z. Lou, M. Fujitsuka and T. Majima, J. Phys. Chem. Lett., 2017, 8, 844-849.

54 Y. T. Chen, F. Guo, A. Jachak, S. P. Kim, D. Datta, J. Y. Liu, I. Kulaots, C. Vaslet, H. D. Jang, J. X. Huang, A. Kane, V. B. Shenoy and R. H. Hurt, Nano Lett., 2012, 12, 1996-2002.

55 I. V. Lightcap, T. H. Kosel and P. V. Kamat, Nano Lett., 2010, 10, 577-583.

56 J. Lee, J. C. Park and H. Song, Adv. Mater., 2008, 20, 15231528.

57 Y. Lu, Y. Mei, M. Drechsler and M. Ballauff, Angew. Chem., Int. Ed., 2006, 45, 813-816.

58 Q. Zhang, T. R. Zhang, J. P. Ge and Y. D. Yin, Nano Lett., 2008, 8, 2867-2871. 